\title{
Reforming Telecom Regulation: An Essay Review of Nuechterlein and Weiser's Digital Crossroads ${ }^{\dagger}$
}

\author{
MARIUS SCHWARTZ * \\ Department of Economics, Georgetown University
}

\begin{abstract}
The U.S. telecom industry has long been evolving from regulated monopoly to competition in various services such as telephony and video. This trend is accelerating with the spread of digital transmission and the Internet. Digital Crossroads provides a timely and sweeping treatment of the entire industry, focusing on the interaction between regulatory policy and competition - lessons from the past, and the challenges ahead. This essay review synthesizes and extends the book's contributions around two central policy prescriptions: adopt a high intervention threshold before mandating "nondiscriminatory" access to perceived bottleneck facilities, and eliminate a host of outdated and arbitrary regulatory distinctions.
\end{abstract}

\section{Introduction}

U.S. telecommunications policy is a tough nut to crack. It is a witch's brew of several disciplines - economics, technology, law, and regulatory institutions (not necessarily in order of importance) - arcane materials (try reading the 1996 Telecom Act from scratch), and ubiquitous jargon. Moreover, no single source provides an accessible treatment of all the industry segments since academics and practitioners have tended to specialize in particular services or technologies - for example, wireline telephony, cable television, broadcasting, or mobile wireless - that are subject to different regulations. This compartmentalization is increasingly strained by the ability of different transmission conduits to deliver competing services. For example, mobile wireless competes with wireline for phone service; cable competes with satellite for video distribution; cable

\footnotetext{
${ }^{\dagger}$ Jonathan E. Nuechterlein and Philip J. Weiser, Digital Crossroads: American Telecommunications Policy in the Internet Age, MIT Press, 2007. The authors are lawyers with deep telecom expertise. Nuechterlein is a partner at Wilmer Cutler Pickering Hale and Dorr LLP, and served as Deputy General Counsel of the Federal Communications Commission in 2000-2001. Weiser is Professor of Law and Telecommunications at the University of Colorado and Executive Director of the Silicon Flatirons Telecommunications Program, and served as principal telecom adviser to Assistant Attorney General Joel Klein at the Antitrust Division, U.S. Department of Justice.

* Professor of Economics, Georgetown University, Washington DC 20057-1036. E-mail:

Schwarm2@georgetown.edu For valuable input, I thank Patrick Brogan, Richard Clarke, Tom Hazlett, Bob Majure, Federico Mini, John Nuechterlein, Scott Wallsten, Phil Weiser, and John Williams. The usual disclaimer applies.
} 
modems and digital subscriber lines (DSL) compete in broadband Internet access and can each support a host of digital services (voice, video, data, or hybrids).

This book does a remarkable job of elucidating the field. Lawyers by training, the authors convey deep knowledge of legal and institutional aspects, but also a sound grasp of the economics and technology relevant to the key policy issues. They provide a sweeping view of the entire industry, both as it evolved historically and where it is headed, while highlighting the policy challenges. Despite the dense subject matter, the exposition is remarkably accessible: the writing is hard-hitting and largely free of jargon, and there is a useful glossary of telecom terms. As a one-stop exposure to U.S. telecom policy it is hard to beat.

Given the book's broad scope, I start in section 2 with a brief overview of the topics covered, my fairly minor quibbles, and the book's value to various audiences. In section 3 , I summarize the central themes and main policy proposals - more circumspect regulation and elimination of artificial regulatory distinctions. I then flesh out some of the bases for these proposals: section 4 addresses the record of interventions seeking "nondiscriminatory" access to bottlenecks; section 5 addresses artificial distinctions. In each case, I synthesize examples that are interspersed across chapters and highlight the economic issues. Section 6 concludes with a closer look at the reform proposals, especially their institutional aspects.

\section{What, how, for whom}

\subsection{Topics covered}

Chapter 1 provides useful industry background and overviews the central themes. Chapters 2 and 3 address the traditional "wireline" telephone network. Historically, this has been a central focus of U.S. telecom policy, especially the largely monopolized "last mile" links to residential and small business customers ("mass market"). The book covers various milestones: the introduction of competition in consumer equipment in the 1970s, the emergence of long-distance competition, the 1984 breakup of AT\&T, and the 1996 Telecom Act and its messy aftermath.

Chapters 4 through 6 discuss where the industry is headed: delivery of all traditional telecom services - voice, data, and video - in digital form over common facilities often making some use of Internet protocols. Chapter 4 provides useful background on digital transmission and the Internet. Chapter 6 illustrates the Internet's power to increase competition in traditional services with the example of Voice over Internet Protocol (VoIP) that has diverted millions of customers from traditional telephone networks. Good Internet access, however, and the ability to add services like VoIP, requires transmission facilities with sufficient capacity ("bandwidth") end-to-end, including in the last mile - "broadband access". Today, residential broadband in most local markets is mainly offered by two providers: a telephone company and a cable company. Chapter 5 and the book's preface discuss a major ongoing controversy, falling under the broader heading of "Net Neutrality": should these competing broadband providers be regulated in how they deliver and price various Internet traffic? 
Moving from landline networks, the next two chapters cover an alternative delivery medium: the airwaves. Chapter 7 discusses how the government manages transmission rights in the electromagnetic spectrum. Traditionally, command-and-control methods were the norm; the Federal Communications Commission (FCC) "zoned" certain frequencies for rigidly specified uses, resulting in costly misallocation. (As a vivid example, spectrum used for cellular phone service was valued twenty times higher than spectrum restricted to serve only taxi dispatch). Over time, the FCC adopted more market-friendly approaches, such as granting more flexibility in use, assigning mobile wireless spectrum through auctions, and allowing secondary market trading. But the authors and other observers agree that more needs to be done (Kwerel and Williams, 1998 and Hazlett, 2008). Chapter 8 analyzes a major success story - the spectacular growth of mobile wireless ("cellular") services, which the authors attribute partly to the lighter regulation adopted here than in wireline telephony.

Chapter 9 reviews intercarrier compensation - the arcane rules governing charges for traffic exchanged between carriers (mainly termination charges) - and distortions created by the myriad of regulatory distinctions among various calls (for example, local, longdistance, wireless). Chapter 10 addresses the related issue of universal service, which traditionally involved holding regulated local telephone company rates below cost for certain customers (mainly residential in low-density areas) and offsetting the deficit through above-cost rates for other customers (for example, businesses in urban areas) or services (notably, access charges for long-distance calls). Like intercarrier compensation, the cross-subsidy approach to universal service, and its incomplete replacement by an explicit fund to which only some carriers contribute, are under increasing pressure due to changes in technology (that, for example, blur the lines between "local" and "long distance") and the growth of competition. Both are in serious need of reform.

Chapter 11 addresses television services. It discusses, inter alia, regulation of competing video delivery platforms - over-the-air "free" broadcasting, cable, and directto-home satellite - including the duty of cable systems to carry all broadcast signals, and of cable companies that also own programming to provide program access for satellite competitors. Chapter 12 covers telecom standards and the tradeoffs from intervention (for example, mandating a standard can avoid standard wars and splintering, but can yield the wrong choice or sacrifice valuable variety.) It provides informative case studies of standards adoption in color TV and mobile wireless, and of the political economy issues in the lengthy transition from analog to digital TV broadcasting (analog broadcasts are finally scheduled to end in February 2009).

Chapter 13 concludes with policy recommendations, including the appropriate roles of the FCC and other bodies.

\subsection{Some quibbles}

The book exceeds 650 pages, partly because some points are repeated. This duplication can be a bit tedious if the book is read end to end; but it makes the book more modular, and thus accessible to readers who are interested in only certain chapters.

Second, the discussion could have been enlivened with a few more illustrative statistics to convey a sense of the relevant magnitudes, for example, the size of access charges paid by long-distance carriers (see section 5.3 below) and the extent of telephone land lines lost to competitive alternatives such as wireless and cable. In addition, the phrasing of a few 
economic points is a bit imprecise. But this is largely a matter of phrasing, not substance; the authors' discussion of economics is generally sound, certainly on the big points.

Third, some of the rhetoric tilts towards incumbent telephone companies, notably, on the 1996 Act's unbundling requirements and the duties imposed on telephone but not cable companies for their competing broadband access products. That said, many observers agree in hindsight that the Act's unbundling mandates and their implementation were excessive and less successful than hoped; and the disparate treatment of DSL vs. cable (largely eliminated in 2005) could not be justified on market power grounds. Plus, the rhetoric makes for livelier reading!

Finally, the book focuses heavily on the FCC. For example, while state public utility commissions (PUCs) did much of the heavy lifting to implement the local competition mandates of the 1996 Act by overseeing the development and pricing of complex new access arrangements for competitors, the discussion of these efforts is rather sparse. Overall, however, focusing on the FCC as the main federal regulator makes sense because rational telecom policy in the Internet era will increasingly have to be managed at the federal rather than state level.

In the broad scheme of things, these are minor quibbles that should not obscure the book's achievement. It offers a sweeping, sophisticated, and highly informed treatment of policy issues in a complex and rapidly changing industry so central to modern economies.

\subsection{Suitable audiences}

Since the book's original publication in early 2005, there have been some notable industry changes. For example, the largest "local” phone companies, SBC and Verizon, acquired the two major long-distance companies, AT\&T and MCI, respectively. The authors nicely summarize these developments in the preface to the November 2007 edition and identify the various chapters implicated. Few major changes have occurred since then (I discuss one in section 4.6), so the book is largely up to date. Moreover, the themes it addresses are enduring.

Potential readers should be aware that the book focuses heavily on legal and institutional aspects, such as the FCC's jurisdictional authority and various regulatory skirmishes. Masochism aside, why should one care about these details and the horrors of the past? A direct reason is that many of the rules still apply and need reforming. In addition, and no less important, the historical experience can be a valuable guide for assessing future interventions. Finally, an appreciation of the legal, institutional and political context of U.S. telecom policy is vital for anyone who is serious about the field.

I see several uses for the book. Its broad scope makes it attractive to generalists seeking an overview of the telecom landscape. Readers familiar with some industry segments, such as wireline telephony, can learn about others, such as wireless or video. Even specialists can benefit from the wealth and depth of legal and institutional material assembled in one place, often in treatise-like footnotes. For teaching, the book can serve as the main text in a course on telecommunications, or as a supplement in courses on competition, regulation, or political economy to provide interesting context and case studies. 


\section{Central themes}

\subsection{Monopoly sources and leverage concerns}

Chapter 1 frames the key issues. The authors define "telecommunications" as the transmission of various types of information (voice, video, data) using electromagnetic signals over any conduits, including the airwaves. This definition identifies the book's broad scope. The authors explicitly focus on telecom policy motivated by concerns with market power (rather than diversity or localism, goals that are less well defined but traditionally pursued in media policy).

Broadly, the history of U.S. telecom policy has been a move from vertically integrated monopoly towards increased competition in various segments. The authors recap two industry features that can create market power and may justify policy intervention: scale economies on the supply side, and network effects on the demand side for certain services (such as telephony). These features are hardly unique to telecommunications but are prominent there.

Network effects stem from users' demand for broad connectivity, and often can be shared among competitors through interconnection - physical and financial arrangements to exchange traffic. Interconnection can emerge voluntarily where no single carrier has a high enough share of the relevant users, as among major Internet backbones (longdistance, high-capacity carriers of Internet traffic that exchange traffic at unregulated zero reciprocal charges, or "peering”). As the authors note, however, the case for mandated interconnection is strong for traditional local phone companies that amassed a predominant share of users under a franchise monopoly regime and could foil competitors by impeding interconnection. Concerns with network effects have also prompted well-known interventions to enforce compatibility by dominant platforms besides telecom carriers, such as Microsoft and its Windows operating system.

Scale economies arise in telecom networks because of large fixed costs compared to the relevant demand, especially in networks that use land-based (or "wireline") conduits. The degree of scale economies varies in different parts of such networks depending on the scope for aggregating traffic. Long-distance transport facilities can typically support multiple competitors, while the last-mile access loop to small customers has typically been viewed as the strongest natural monopoly element. Of course, the distinction between loop and transport facilities is not always sharp, and the importance of scale economies as an obstacle to competition can change with growth in demand or technological change that reduces fixed costs. For many years the telephone industry was a regulated franchise monopoly, in part because of the perceived natural monopoly conditions. As the authors emphasize, however, this regime also allowed regulators to pursue in the name of "universal service" various social goals through mandates on telephone companies, notably cross-subsidies unrelated to genuine universal service.

Around the early 1970s, policy attitudes began to shift, especially at the federal level, towards encouraging competition in segments of the telephone industry that were not natural monopolies, such as customer equipment and long-distance service. However, these "adjacent" segments were strongly complementary (or "vertically-related") to the persisting core monopoly in the local exchange. This raises a policy concern - generic to many regulated industries - with monopoly leverage: the bottleneck owner may impede competition in adjacent markets by discriminating in bottleneck access to favor of its own 
affiliates (or other preferred partners) in those markets. (Such discrimination incentives may arise in large part due to the nature of the price regulation itself; see section 4.2 below.) Monopoly leverage concerns are a recurring theme throughout the book. They underlie many of the prominent U.S. regulatory interventions (sections 4.3 and 4.4), and permeate U.S. telecom policy to this day, including the Net Neutrality controversy (sections 4.5 and 4.6). Importantly, the ability to exercise leverage diminishes with the rise of technologies that provide an alternative to the bottleneck as discussed next.

\subsection{Convergence: Digital transmission, the Internet, and implications}

Like the rest of us, the authors can't resist the overused term “convergence”. However, the phenomenon is quite real in telecom and has major implications for policy. Convergence, or what the authors sometimes call "cross-platform competition," refers here to changes that allow a given service to be delivered using different technologies. For example, distribution of television programming was initially through over-the-air broadcasting, but later predominantly over landline cable facilities (and later still, also via direct-to-home satellite broadcasts). Telephony was initially provided through landline networks but later increasingly through mobile wireless. All these examples initially took place without digital transmission. But the authors usefully explain why digitization and the Internet promise to greatly magnify convergence.

Historically, telecom services were delivered using analog transmission: information is sent through electric currents via continuous waveforms that mimic (are "analogous" to) the original signal. ${ }^{1}$ Digital transmission, instead, represents the relevant parameters of a signal by numbers ("digits"), for example, the amplitude of waves in a voice call. ${ }^{2}$ The representation is transmitted as data packets that are re-assembled into the right order at the other end and decoded using the common protocols. Digital transmission offers important advantages. It economizes on capacity for several reasons: data packets can be co-mingled on a given digital circuit; ${ }^{3}$ compression techniques can be used; and dynamic routing can be employed - sending packets over different paths to the same destination depending on which path is less congested at that moment - as typically done in the public Internet. Digital transmission can also offer greater clarity, because it essentially sends instructions on how to re-construct the signals rather than seeking to mimic them as in analog

\footnotetext{
${ }^{1}$ The authors give the example of an analog telephone call. The speaker's voice creates continuous pressure waves of air particles, which are converted into analogous variations of electrical current, and converted back at the receiver end into continuous pressure waves that create audible sound.

${ }^{2}$ An arbitrarily close representation can be obtained as long as (1) sufficient granularity is provided (for example, when sampling a wave's amplitude) and (2) sufficiently frequent samples are taken.

Communicating more such information requires greater capacity, or "bandwidth". In principle, the relevant numbers could be expressed using any mathematical base, but in practice digital transmission has been binary since it is natural to build digital circuits as binary circuits (with 0 and 1 corresponding to on/off states).

${ }^{3}$ And the packets can contain different digital content, such as voice or video. In a traditional circuitswitched telephone network, capacity (a "circuit”) is used exclusively by a particular call for its duration. Circuit-switched transmission can be analog or digital, but is increasingly digital (because of its other advantages). Packet-switched transmission is inherently digital. Observe that the physical distinction between data networks (including the Internet) and the circuit-switched telephone network lies in the switching equipment (packet-switches or "routers" versus circuit switches) rather than the "pipes" since the same conduits often support multiple transmission modes.
} 
transmissions (where signals may be distorted in various ways). Finally, digital signals can readily be used by computers, enabling new hybrid services.

Telephone companies and some corporations have long used digital transmission within their networks. Digital transmission was adopted in the 1980s and early 1990s for consumer services, such as mobile voice, radio broadcasts, and video transmission by cable and direct-to-home satellites. However, the subsequent spread of the Internet gives digital convergence a major boost. The Internet is a packet-switched method of communicating between computers using a particular set of logical protocols (TCP for transmission functions, IP for addressing). The physical links can be over any conduit that offers sufficient capacity. Additional protocols can be overlaid on the basic TCP/IP layer to support applications such as Email, Web access, and Voice over IP (VoIP). Although the Internet existed in a limited form since the 1970s, it spread to the mass market only in the 1990s after its privatization by the U.S. government and the emergence of user-friendly applications and interfaces, notably, Email programs like Eudora or Outlook and Web browsers like Navigator or Explorer.

Initially, U.S. residential consumers obtained Internet access using slow dial-up connections over analog phone lines. In the late 1990s, cable and telephone companies both upgraded their networks to offer broadband ("fast") Internet access as a new service, putting these previously non-competing "pipes into the home” in direct rivalry.

Moreover, the proliferation of the Internet made it economical to exploit its basic standards and overlay additional services traditionally delivered over distinct facilities. VoIP was the first major such service. Indeed, cable companies only offered voice service on a large scale, in competition with traditional phone company service, after adopting VoIP that shared certain economies with their packet-switched network used for Internet access. Other IP-based services are likely to follow since the Internet can be used to transmit any digital content at good quality over any conduit that has enough end-to-end capacity. For example, AT\&T is marketing an IPTV service to compete with regular cable company video offerings. And as advanced mobile wireless networks are deployed with greater capacity, one can expect them eventually to offer a full panoply of digital services exploiting to varying degrees the core Internet protocols.

This current and prospective convergence has two broad implications for economically- rational regulatory policy. First, it fosters competition among conduits for the delivery of any telecom service, thereby reducing the need to regulate conduits. Second, it calls for consistent treatment of the newly competing technologies and services (with a possible transition exception for residually dominant firms). The authors argue that U.S. telecom law and policy are seriously flawed on both counts (see, especially, chapters 1 and 13).

Specifically, they see an excessive tendency to regulate and urge a higher hurdle for intervention. Besides the scope for convergence to erode bottlenecks, this view rests on another salient fact: the problematic record of access regulation in complex environments, epitomized by the unbundling provisions of the 1996 Act. (When I asked a longtime telecom observer how to document that the Act has been excessively regulatory and disappointing, he replied: “Ask any sane person.”) I flesh out the book’s lessons on access regulation in section 4 below.

The authors also stress the host of artificial regulatory distinctions notably, but not solely, between competitors that use different transmission technologies. These and other distinctions have become increasingly strained. I highlight these issues in section 5. 


\section{4 "Nondiscriminatory" access to perceived bottlenecks}

\subsection{Some caveats}

In the preface, the authors rightly portray the Net Neutrality controversy - over access to broadband networks for various Internet content and applications - as the fiercest battle in telecom policy. Yet disputes over access are as old as the hills; like Zeus, they show up in various disguises. In assessing the Net Neutrality issue, and others like it that will surely follow, the historical record of regulatory interventions detailed in the book can yield useful lessons. But first, some general observations.

The issue of nondiscriminatory access typically arises in regulatory settings when a monopolist provider of a key facility or service, the "bottleneck", operates also in strongly complementary ("adjacent") markets where other firms can potentially compete provided they (or their customers, depending on the institutional arrangement) obtain good and appropriately priced access to the bottleneck. The typical remedy is to require the monopolist to provide such nondiscriminatory access to competitors and to its own affiliate (more on this below).

While the terms "nondiscriminatory" and "bottlenecks" are widely invoked in policy debates, their meaning in practice can be far from self-evident. Nondiscrimination is the core tenet of traditional common carrier regulation, and essentially requires the provider to offer similar terms to similarly situated parties. However, "similarly situated" can be an elusive concept, as evidenced by experience with the Robinson-Patman Act, the main U.S. antitrust law against price discrimination that threatens competition (Schwartz, 1986). The concept of nondiscriminatory pricing of access as between a monopolist's affiliate and its competitors is also problematic.

What constitutes a "bottleneck" can be controversial too. The 1996 Act spawned extensive disputes over which of a telephone company's network elements should be made available on an unbundled basis to rivals because otherwise their ability to compete would be "impaired". This impairment standard envisions something between access being "vital" because duplicating the facility is prohibitive versus "nice to have" at a low price. But where should the line be drawn? Setting the bar high can allow the firm to foreclose competitors if it so wishes. Setting the bar low risks incessant intervention, as well as reduced investment by that firm. In antitrust, the Essential Facility doctrine and its scope have been controversial for these reasons (Areeda, 1990).

Finally, the identity of potential bottlenecks is context specific. Traditional concerns in telecom have centered on landline transmission facilities, especially the last mile. However, the locus of concern can shift. For example, when direct-to-home satellite broadcasting emerged as a rival conduit to cable for distributing multi-channel video programming, Congress feared that cable companies that also owned programming would foreclose satellite competitors by denying them access to such programming. To address this perceived bottleneck, the 1992 Cable Act imposed the Program Access Rules (see chapter 11; the rules were extended in 2007 for five years).

\subsection{Asymmetric price regulation and monopoly leverage incentives}

Assuming a genuine bottleneck, does its owner always have strong incentives to exclude independents from adjacent segments? The authors usefully recap the profit tradeoffs 
(chapter 1; see also Farrell and Weiser, 2003). Importantly, an unregulated monopolist need not have strong exclusionary incentives, because raising price or reducing quality or variety in complementary segments will reduce demand for and profit from the monopolist's core product. Depending on the setting, there may be opposing incentives too, for example, when exclusion shifts profit from competitors to the monopolist's affiliate or facilitates price discrimination in the adjacent markets. Another example is when adjacent-market rivals threaten the core monopoly, the crux of the antitrust case brought by the Department of Justice (DOJ) against Microsoft. ${ }^{4}$ On balance, however, there is no general rule that an unregulated monopolist will have strong incentives to discriminate in access against adjacent market competitors, because of the aforementioned demand reduction effect.

A well-known exception arises if the monopolist is subject to a certain pattern of price regulation: the margin it can charge adjacent-product competitors for access to its monopoly service is more tightly regulated than the margins it can charge if it sells the adjacent services itself bundled with the monopoly one (Brennan, 1986). This pattern can arise, for example, if adjacent markets are used to finance cross-subsidies (for example, long-distance calls cross-subsidized local calls); or from a belief that regulation of the firm's margins in adjacent segments is not needed once competitors are entitled to access its monopoly service at a low regulated price. Whatever the reason, such regulation that lets the firm earn higher margins by selling adjacent services itself than by selling access to competitors will bias the firm against the latter (Laffont and Tirole, 2000). The firm then has a clear incentive to handicap competitors through various forms of non-price discrimination in access ("technological” or "operational” discrimination).

\subsection{Access interventions before the 1996 Act}

Many of the landmark regulatory interventions leading up to the 1996 Act targeted concerns with monopoly leverage in the telephone industry consistent with the above incentives (chapters 1, 2 and 5). Since the early 1900s, telephone service to most U.S. consumers was a monopoly controlled by the vertically integrated Bell system of the original AT\& $\mathrm{T}^{5}$ - the local Bell companies, AT\&T Long Lines, and the equipment arm Western Electric. The core monopoly was local exchange networks, protected by exclusive franchises and natural monopoly characteristics. Margins on basic residential local service were kept much lower than (and cross-subsidized by) other services such as lines to business customers, long-distance service, and equipment rental. Over time, the inflated margins coupled with changes in demand and technology attracted attempted entry, which the incumbent phone companies predictably resisted.

Customer Premises Equipment (CPE, also called terminal equipment), such as basic phones and more sophisticated devices, arguably is the most successful U.S. example of equal access intervention (Brock, 1994). The FCC required that devices supplied by independents, including Western Electric's competitors, be allowed to connect with the telephone network provided they met certain specifications, spelt out in the Part 68 rules of 1975, to prevent technical harm to the network. For example, phones had been hard wired

\footnotetext{
${ }^{4}$ Microsoft feared Netscape’s browser because it could help distribute Sun's Java software, which in turn could allow applications written for Windows to run on competing operating systems. This would erode the “applications barriers to entry” that protected Windows (Gilbert and Katz, 2001; Klein 2001).

${ }^{5}$ Not to be confused with the many subsequent namesakes; for an amusing and almost accurate history of “AT\&T” watch Stephen Colbert at <http://www.youtube.com/watch?v=YtFtcp4mNzA>
} 
to the network, and the new rules instead introduced the familiar standard phone jack. (Undoubtedly, the jack will not be so familiar to our wireless-only grandchildren ...). The FCC's efforts are widely credited with facilitating a wave of competitive entry that reduced prices and greatly increased product variety.

Although formulating the technical rules took considerable time and effort, several factors made this intervention relatively easy compared to subsequent efforts (Brock, 1994), and it would have been helpful for the authors to note these factors. First, the interface between terminal equipment and the telephone network was relatively simple. Second, the interface was also stable, since the telephone network was technologically mature. Finally, no payments needed to be determined from CPE competitors to the network owner - access involved only technical standards, not pricing.

Long distance phone service - the transport of calls on high-volume routes, typically between cities - was another important service that attracted competitive entry. After initially targeting only point-to-point links between large business customers, since the 1970s entrants such as MCI and Sprint expanded into mass market retail offerings that required interconnection with AT\&T's monopoly local exchange networks. AT\&T sought to undermine them and protect its long-distance business (where regulators let it charge higher margins than on local calls). A host of disputes ensued over interconnection (and over AT\&T's retail price responses to entry), prompting the DOJ to file an antitrust suit in 1974 charging AT\&T with monopolization. By the time of the trial, the DOJ came to the view that if AT\&T remained vertically integrated, securing nondiscriminatory access for long-distance competitors was impractical or would require excessively intrusive and ongoing regulation of a myriad of technical and operational dimensions. (This view was supported by the FCC's Common Carrier Bureau Chief who testified at the trial that the FCC could not effectively regulate AT\&T; see Brock, 1994, p.135).)

The suit was resolved with a consent decree (the "divestiture"), entered in 1982 and effective 1984. The integrated company was separated into (a) the potentially competitive equipment and long-distance segments which retained the name AT\&T and eventually were largely deregulated, and (b) the monopoly local phone operations that became the seven Regional Bell Operating Companies (RBOCs). To prevent the perceived problem from recurring, the RBOCs were barred from entering the potentially competitive segments. The divestiture ultimately resulted in a system that ensured equal access to local networks for all long-distance carriers - "interexchange carriers" (IXCs) - and competitors succeeded in growing at the expense of the now-separated AT\&T. But the divestiture also sacrificed efficiencies of integration, notably by forcing an increasingly artificial separation between "local" and "long-distance" segments. ${ }^{6}$

The FCC's Computer Inquiries sought to achieve nondiscriminatory access without forcing corporate separation (chapter 5). The Computer Inquiries were orders issued in the 1970 s and 1980s to govern interactions between telephone companies and the emerging data processing industry that relies on telephone transmission as a key input. Early examples include voicemail and information services provided by firms like CompuServe. To avoid saddling the emerging services with burdensome common carrier regulation, the FCC's Computer II order of 1981 distinguished "basic" telephone transmission services

\footnotetext{
${ }^{6}$ The consent decree defined about 170 regions called LATAs (Local Access and Transport Areas) and confined RBOCs to offering intraLATA calls. "Local” calls in this context mean "intraLATA" which typically is considerably broader than a single local exchange. The 1996 Act later defined "local” traffic more narrowly.
} 
from "enhanced" services that employ also computer processing and confined common carrier regulation to the former. ${ }^{7}$ Computer II let telephone companies enter enhanced services, but required unbundling: a telephone company was required to offer basic transmission functions separately from enhanced services, on a nondiscriminatory tariff basis to all unaffiliated entities and its own enhanced-service operation. The latter had to be a separate affiliate (a condition dropped in Computer III) to facilitate monitoring of nondiscrimination.

But what is the economic meaning of nondiscriminatory pricing to an affiliate? The authors should have flagged this question. When dealing with an affiliate and its competitors, there is a fundamental economic difference between nondiscrimination in technical terms - sometimes termed “equal access" - and in pricing. Equal (technical) access is conceptually clear: all parties must be served in the same way. Nondiscriminatory access pricing does not have the same bite. Although the affiliate pays the same tariff rate as competitors, it will treat this as purely an internal transfer price if its goal is to maximize overall firm profit. Unless there are mechanisms that induce the affiliate to behave as an independent profit center, it is not clear what is added by requiring it to pay "nondiscriminatory" access prices.

One possibility is that the affiliate is ordered to treat the access price as a cost when setting its retail prices ("imputation" rules). Enforcing such rules would then require regulating the affiliate's retail prices, for example, mandating a price floor to prevent a

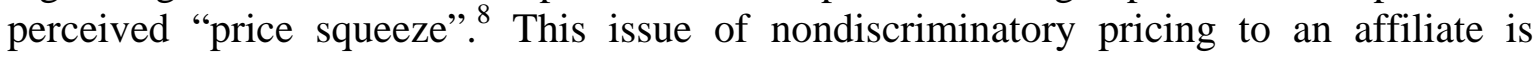
common in regulation generally and recurs in the book. One instance is RBOC pricing to their long-distance affiliates and to independent IXCs after the 1996 Act (chapter 3). Another is the FCC's Program Access Rules for cable companies that are vertically integrated into programming (chapter 11). Some discussion of whether and how regulation has put teeth in nondiscriminatory pricing to affiliates would have been valuable.

Was the Computer II regime effective? Yes, in the limited sense that it prevented phone companies from making significant headway in enhanced services. However, ensuring nondiscriminatory access for competitors may have sacrificed efficiencies of vertical integration. Potentially, the phone companies may have been able to offer some enhanced services more efficiently by exploiting economies of scope internal to an integrated firm instead of having to mimic the operation of independent firms under the unbundling rules. As computer technology spread within telephone networks, the FCC grew increasingly skeptical of the feasibility and value of the rigid distinction between "basic” and “enhanced” services (Brock 1994).

\subsection{The 1996 Act and unbundled network elements}

The Telecom Act of 1996 was a landmark event, the first comprehensive overhaul of U.S. telecom laws in 60 years and an ambitious regulatory experiment in network unbundling (Farrell, 1996; Katz, 1997; Schwartz, 1997). Much of its focus was on the traditional (circuit-switched) telephone industry, and the book provides an illuminating account of this experience (chapter 3).

\footnotetext{
7 The 1996 Act incorporates this regulatory distinction under the different names "telecommunications" versus “information" services, as discussed further in section 5 below.

8 This highlights the flaw in arguments sometimes touted as "regulation lite" - that competitors do not seek regulation of any price level but merely to get the same access price as the affiliate.
} 
In telephony, the Act reflects two main and related goals: ultimately to end monopoly in the local exchange (promote "local competition") and, when sufficient progress was made on that path, let the RBOCs offer long-distance services. Three major steps were taken to foster local competition. First, the Act pre-empts most state and local exclusive regulatory obstacles to competition, including exclusive franchises. Second, to address network effects, interconnection is mandated between any incumbent local exchange carrier (ILEC) and competing local exchange carrier (CLEC), and termination rates for "local" traffic must be equal between carriers (reciprocal compensation) and in theory not exceed the incremental cost of termination. Third, any ILEC (except small rural carriers) must allow CLECs to (a) buy the ILEC's retail services at discounted prices for resale by the CLEC, and (b) to lease capacity on unbundled network elements (UNEs), for example, on the loop connecting a customer with the ILEC's central office where the CLEC could collocate its switching equipment.

After an RBOC has done enough to comply with the network-sharing (unbundling) provisions in a given state, as judged by the FCC with significant input from the state commission and the DOJ, it could offer long-distance services in that state. The economic logic for this conditioning is to prevent RBOC leverage into long-distance services if allowed to enter while still possessing monopoly over local networks (the pre-divestiture scenario) and, many would argue, to increase RBOC incentive to comply with the network sharing provisions. Predictably, intense disputes erupted between RBOCs and IXCs, as well as CLECs over precisely what was required of the RBOCs and whether these requirements were met, but by 2003 the RBOCs obtained long-distance authority in all states and rapidly gained market share from IXCs.

The unbundling provisions proved the most contentious and problematic. Their economic rationale is that an ILEC enjoys large economies of scale that entrants cannot rapidly duplicate but perhaps could efficiently share with the ILEC. At the time of the Act, it was plausible to think that parts of the local exchange network could remain a natural monopoly for some time, notably loops to residential customers. ${ }^{9}$ If so, entrants may still be able to compete for local exchange service by providing some facilities, such as switching equipment, while leasing others from the ILEC, such as loops. Even for some facilities that were not a natural monopoly, an ILEC enjoyed large economies of density that entrants could share by leasing capacity until they achieved sufficient volume (for example, shared transport between central offices where traffic is aggregated).

Resale of an ILEC's retail services (as distinct from leasing facilities) may be beneficial because it lets entrants fill in their offerings while they build facilities, or because entrants conceivably may offer valuable competition in marketing or other retailing functions even if they do not build facilities (a point the authors overlook). The Act specifies that the resale discount to CLECs off the ILEC's retail prices should reflect the costs avoided by the ILEC when it delegates retailing functions to a CLEC. Regulators and the courts agreed fairly early that the avoided costs are modest, in part because many of the ILEC's retailing costs such as billing systems are fixed, and the ensuing resale discounts made the resale option uneconomical in most cases.

UNEs, however, prompted fierce and protracted controversies, over the scope of the FCC's authority, the appropriate prices, and the range of elements subject to unbundling.

\footnotetext{
${ }^{9}$ The cable companies also had such last mile links and the Act envisioned them offering circuit-switched phone service. As noted, however, the cable companies in fact only offered voice service on a large scale some eight years later after adopting VoIP technology.
} 
Regarding authority, the traditional model in telephony divided jurisdiction between the FCC and state PUCs based on the interstate/intrastate service split. The Act introduced a new division of labor whereby the FCC formulates the broad rules for access by competitors to incumbents' facilities and PUCs implement the details, including actual prices. However, the $8^{\text {th }}$ Circuit ruled in 1996 that the FCC lacked authority because local exchange competition is inherently intrastate. It colorfully proclaimed that the Act "is hog tight, horse high, and bull strong" on this point - only to be reversed by the Supreme Court's Iowa Utilities Board decision in 1999.

On pricing principles, the Act merely states that the rates for leasing UNEs should be "based on the cost" of providing them. The FCC's 1996 order implementing the Act's local competition provisions specified a methodology called TELRIC (Total Element Long Run Incremental Cost) that estimates the cost of various elements for a new network rather than the ILEC's historical costs (Appendix A discusses TELRIC and alternative methodologies). After Iowa Utilities Board, another round of litigation ensued over whether the TELRIC methodology is unconstitutional because it inherently denies incumbents the ability to recover past investment, until the Supreme Court upheld it in 2002 (Verizon v. FCC).

Which network elements should be made available to competitors? Again, the Act is vague. The FCC must consider "at a minimum, whether ... failure to provide access" to the particular element "would impair the ability" of the requesting carrier to offer its services. This impairment standard calls for some threshold of importance, but let the FCC draw the line. Most observers would include loops and, perhaps, shared transport, but then things get murkier. The FCC added switching and other elements, as well as the right to lease capacity on all the network elements - the UNE Platform (UNE-P). ${ }^{10}$

There was a credible case for allowing the UNE-P: it enabled IXCs to compete on a roughly equal footing against ILECs in offering integrated packages of local and longdistance services. Using the UNE-P, AT\&T, MCI and Sprint (all IXCs at the time) captured millions of customers for all-distance service. However, mandated network sharing also has its downsides, including transaction costs and the risk of reduced investment incentives for incumbents, and courts grew skeptical of the FCC's expansive approach to the impairment standard. After several rounds of litigation, in June 2004, the D.C. Circuit removed switching from the list of unbundled elements, thereby effectively ending the availability of UNE-P after a phase-out period. ${ }^{11}$

The demise of UNE-P quickly prompted the major IXCs to stop marketing to new residential customers, signalling a retreat from the mass market. This softened regulatory objections to ILEC-IXC mergers. In 2005, SBC acquired AT\&T and Verizon acquired MCI, drastically shrinking the independent long-distance industry that had developed since the AT\&T divestiture.

\footnotetext{
${ }^{10}$ Unlike resale, UNE-P is eligible for TELRIC pricing. Another key difference is that resale applies only to an ILEC's retail services, hence excludes access sold to IXCs. By leasing the UNE-P at TELRIC rates, an IXC (in its dual capacity as a CLEC) avoids paying inflated access charges on long-distance calls that it originates, and collects such charges on calls it terminates from other IXCs to its customers.

11 The Supreme Court found in Iowa Utilities Board that the FCC had mandated unbundling of too many elements. The FCC revised its list but was rejected again by the D.C. Circuit in 2002 (USTA I). The FCC responded by defending inclusion of switching elements, and UNE-P, not on grounds that switches are a natural monopoly but that physical separation of the incumbent's switch from loops and re-connecting to the entrant's switch - "hot cuts" - can be presumed too cumbersome to keep up with entrants' demand. The D.C. Circuit rejected this national presumption in its June 2004 decision (USTA II).
} 
Besides the costly legal battles (including countless state-level proceedings) and uncertainty spawned by the Act, the technical and operational challenges of unbundling proved substantial. Traditional telephone networks were designed as integrated systems to serve end users, and it took considerable time and effort to create the new wholesale arrangements to serve competitors as required by the Act. For example, the Act did not foresee the need for "operations support systems" - electronic interfaces between competitors and the incumbent for functions such as ordering and billing - yet establishing such systems proved a key sticking point for providing access to UNEs or resale. Physical unbundling of loops through hot cuts also proved fairly slow and costly, and competitors' use of this UNE-L strategy ended up quite limited. ${ }^{12}$

Finally, as the authors emphasize, the circuit-switched telephone network is being superseded by developments largely unforeseen in the Act: the rise of packet-switched networks and broadband Internet access to residential consumers, where cable companies offer a powerful alternative to telephone companies. This is highly relevant to the Net Neutrality debate.

\subsection{The "net neutrality" controversy}

The debate over Net Neutrality is complex, but I will sketch its key aspects (see also Wu and Yoo, 2006). In its current version, the controversy is over what constraints, if any, should be placed on residential broadband access providers in managing and pricing Internet traffic. ${ }^{13}$ Traditionally, the transmission quality and pricing of Internet traffic was largely uniform, regardless of origin, content or destination. Unlike the circuit-switched telephone network, where intelligence resided largely in the network core, the Internet functioned more as a decentralized "dumb network": routers passively directed data packets to the next router and intelligence was concentrated at the network edge with end users - consumers and providers of content or applications ("applications" for brevity). This "end-to-end" architecture is hailed by many Internet advocates for removing control from network operators. They fear that deviations from this model could allow operators to engage in detrimental discrimination and gain excessive control of Internet applications, and they call for regulation to enforce "Net Neutrality".

The operational meaning of the term, however, is far from clear. Conceptually, it suggests nondiscriminatory access for applications to Internet transmission. But what does that entail? When some Internet traffic requires different network performance than others - in delay, "jitter" (variation in delay), or packet loss - uniform treatment is not neutral. ${ }^{14}$

\footnotetext{
12 The FCC (2007a) reports that the number of unbundled loops at the end of 1999 was about 1 million, rising to 4.2 million at the end of 2002 and staying roughly flat through 2006. (For comparison, unbundled loops-with-switching, as in the UNE-P, peaked at 17 million in June 2004.) CLECs achieved greater penetration using their own last-mile facilities: from 2.7 million lines at the end of 1999 to 6.5 million at the end of 2002 and 11.1 million by the end of 2006. Much of this growth came from use of coaxial cable lines to provide telephone service, mainly to residential customers using VoIP. Cable lines rose from 0.3 million in 1999 to 3.1 million at the end of 2002 and 6.8 million at the end of 2006.

${ }^{13}$ An earlier dispute centered on whether cable companies had to offer "open access" to cable modems for unaffiliated ISPs, as the telephone companies were obliged with DSL under the FCC's Computer II rules. The Supreme Court's Brand X decision of 2005 stated that cable companies were not obliged and, for competitive parity, the FCC rapidly followed in its Wireline Broadband Order by relieving telephone companies of their obligations. (See section 5 below.) Despite some predictions of doom and gloom, there is little evidence thus far that these rulings have threatened the vitality of the Internet.

${ }^{14}$ For this reason, the traditional model is more accurately described as "Net Uniformity".
} 
Network operators seek increased latitude in prioritization and other traffic management, as well as pricing, citing the need to cope efficiently with the explosion of Internet traffic (notably, video) and with the growing diversity of traffic. For example, voice (VoIP) is less tolerant of jitter than is Email. Internet "broadcasting” of radio or video programs is more tolerant of delay than are live interactive communications because broadcast signals can be stored before commencing transmission, creating a buffer that maintains broadcast continuity in case of later delays. Traffic management practices to address such issues offer significant potential benefits (OECD, 2006).

The real debate is not over "equal treatment" but over which differences should be allowed. Two broad concerns have been raised: that broadband providers would use discretion to engage in price discrimination between applications, perhaps under the threat of degrading quality unless a higher price is paid, or in foreclosure of unaffiliated application providers (monopoly leverage).

Price discrimination warrants several remarks. First, the use of prices to allocate congested Internet capacity, such as charging more for higher priority, is not price discrimination in the way economists use the term. Other transmission markets, such as gas pipelines, commonly exhibit different prices for interruptible versus firm capacity rights. Second, setting aside congestion, price discrimination in Internet transmission based on differences in the value across applications or across providers of a given application - like price discrimination generally - has beneficial aspects. For example, barring quality-tiers discrimination would likely induce operators to drop low-demand applications that they would serve under discrimination and could thereby reduce overall welfare (Hermalin and Katz, 2007).

Third, much of the pricing controversy concerns whether broadband networks serving consumers may charge also application providers, such as search engines, that derive revenue mainly from Internet advertising to such consumers. The efficient pricing structure in such two-sided markets is generally complex (Armstrong, 2006 and Rochet and Tirole, 2006). But there is no clear presumption that overall welfare would be maximized by financing residential broadband networks predominantly from fees to consumers as opposed to charges also to the other side.

Moreover, if broadband operators could charge application providers (and, indirectly, online advertisers), they likely would reduce prices to consumers. This implication does not hinge on the degree of competition among broadband providers. It flows simply from the complementarity between the two sides: greater consumer adoption and use of broadband generates higher revenue to application providers. If a broadband operator can share in this revenue by charging applications providers, it will have a greater incentive to promote broadband to consumers by cutting price or offering other inducements. ${ }^{15}$

Foreclosure of independent application providers has not been a major issue thus far because, contrary to some perceptions, there is little evidence that broadband operators have discriminated in access against independent application providers, in part because their own offerings have been fairly limited. As the authors note, however, concerns with access discrimination could intensify as broadband operators expand into Internet applications, such as VoIP. Nevertheless, the authors are appropriately skeptical of preemptive Net Neutrality regulation ahead of a demonstrated competitive problem. They

\footnotetext{
${ }^{15}$ A vivid illustration of this linkage is the decision by AOL, the large ISP, to eliminate its fees to residential subscribers in order to obtain higher rates revenue from online advertisers (WSJ, 2005).
} 
point out several important differences compared to past access interventions (see chapter 5 and Preface).

First, access interventions typically have targeted a monopolist or dominant provider. Today's broadband access industry is qualitatively different. There are already two comparably strong competing platforms, DSL and cable modems. Such a market structure can exhibit conduct ranging from perfect collusion to fierce competition. Since regulation is itself quite costly, the presumption adopted in most sectors of the economy - including those with concentration levels comparable to broadband access - is that antitrust should be the main tool for overseeing firms' conduct whenever competition is possible. It seems unwise to reject this presumption here barring evidence that broadband access was becoming a collusive and durable duopoly. Thus far, such evidence is absent. ${ }^{16}$ Without debating the precise strength of broadband-access competition, available evidence suggests it is considerable, ${ }^{17}$ and there are real competitive prospects from other access technologies, notably wireless. ${ }^{18}$

Second, whereas a traditional local telephone company faced tight price regulation of its access service, pricing by broadband access providers to consumers is not regulated. This dampens their incentive to discriminate against independent providers of the complementary content or applications. The logic is that such discrimination would depress consumer demand for broadband and, importantly, a broadband provider's profit would fall in proportion to its margin above variable cost earned on access (section 4.2). Telephone companies whose access margin was tightly regulated had little to lose from discrimination.

Third, broadband access investment is being undertaken in an unregulated environment and likely faces greater risk than investments made by public utilities under monopoly franchises. Verizon, for example, has announced plans to spend many billions of dollars deploying fiber close to the home, a risky move that has left investors nervous.

Finally, as I emphasized (sections 4.3 and 4.4), the relative efficiency of regulation depends heavily on the technological environment. It would have been useful for the authors to draw out this point further. The historical record of telecom regulation shows that initiatives were relatively successful when the access technology was mature and

\footnotetext{
${ }^{16}$ One must therefore read with caution the authors' statement that "the great hope for broadband competition" is that a third technology "will provide a competitive check on the cable and telephone companies" (chapter 13, p.409). It reflects standard structural presumptions that, all else equal, having more rivals increases competition, but it is not intended as a statement about the actual state of competition or a call for Net Neutrality regulation, as the authors make clear later in the same chapter (p.429).

${ }^{17}$ Some have argued that the U.S. lags other countries in broadband deployment and that this indicates weak competition. For a critical assessment of this deployment claim and the pitfalls of international comparisons see Wallsten (2007).

${ }^{18}$ The FCC (2007b) reports statistics on "high-speed” lines (over 200 kbps in at least one direction, using landline or wireless channels) to residential and business customers. Nationwide, on December 31, 2006 there were 82.5 million high-speed lines, supplied using the following technologies for connecting into the customer premises: cable modem 38.9\% (32 million); ADSL 30.8\%; SDSL and traditional wireline plant 1.2\%, Fiber $1.2 \%$, and All Other 27.8\%. All Other includes mainly Satellite and land-based fixed or mobile wireless (26.5\%), and power lines. For residential customers alone (58.2 million), cable modem served $53.6 \%$ and ADSL $39.1 \%$. At the local level, the percent of zip codes where four or more providers offered service (to business or residential customers) on December 31 of the particular year rose as follows: $10 \%$ in 1999; $40 \%$ in 2002; $51.5 \%$ in 2004; and $82.6 \%$ in 2006. These figures overstate somewhat the number of competitors available to a particular customer, because a provider may not be offering service throughout the zip code locality and because they do not distinguish business from residential customers. Nevertheless, the trends do show a clear increase in the number of competitors.
} 
relatively simple. The prototypical example is the FCC's Part 68 rules. Attempts to regulate deeper in the network, as with the Computer Inquiries and the 1996 Act, were increasingly less successful. Net Neutrality regulation would face an Internet environment that is complex and rapidly changing, both commercially and technologically, and embroil regulators in the unpleasant task of second-guessing decisions such as network-traffic management. Consistent with these arguments, the federal antitrust agencies have both voiced skepticism about Net Neutrality intervention (DOJ, 2007, FTC, 2007).

\subsection{Access regulation in mobile wireless networks?}

Since the book's publication, controversies have also emerged over access to advanced wireless networks that are being deployed to support services beyond traditional voice, such as mobile Internet access. Criticizing various practices of U.S. wireless carriers, Professor Tim Wu (2007) called for imposing Carterfone type regulation that would require any wireless network to allow any device. Citing his paper, Skype (2007) sought "open” access also for software applications, such as VoIP or future IP-based services. Google and other application providers urged the FCC to require that spectrum for advanced wireless networks in the $700 \mathrm{MHz}$ band (to be vacated by the analog TV broadcasters in February 2009) should be auctioned subject to extensive obligations on the winning network operator to grant open access for all third-party devices or applications. The FCC ultimately adopted some such requirements for part of that spectrum. Although these wireless controversies postdate the book, the issues are close enough to its central themes that a few observations are in order.

Access regulation in mobile wireless is even less compelling than in landline broadband. There are four national and several regional wireless competitors, and no evidence of a clear competitive failure. At least for voice services, performance in the U.S. wireless industry compares favorably with that in Europe, notably, in the minutes of use per subscriber, as well as its growth rate (Schwartz and Mini, 2007). "Smart phones" are essentially mini computers, and attempting to impose open access for applications could embroil regulators in especially thorny judgment calls about complex and rapidly changing technology. With competing carriers, it is typically preferable to let each decide on how open its network should be and when. Interestingly, Verizon has announced it will open its network to third-party devices while so far AT\&T has not (Wall Street Journal, 2007). Such diverging approaches offer valuable options to heterogeneous consumers, for example, the greater variety of phones or applications on an open network versus the possibly tighter quality control on a more closed network.

Calls for regulation of mobile wireless are especially ironic given the authors' exhortation in their first chapter: "The ultimate aspiration of telecom policy is to do for the industry generally what the FCC's deregulatory policies have done for wireless specifically."

\section{$5 \quad$ Legacy regulation and artificial distinctions}

\subsection{The convoluted regulatory framework}

The U.S. regulatory framework is complex both in how it assigns jurisdictional responsibility for various telecom facilities or services - between the FCC, states, or local 
authorities - and in their substantive treatment. Yet grasping its main features is important for various policy issues. The book succeeds in making this framework comprehensible (almost ...) to non-lawyers; the summary below draws mainly on chapters 1-3, 5-6 and 8, but any imprecision is purely mine.

In the Communications Act of 1934, Title II governs regulation of wireline telephone companies and divides authority between the FCC and the state public utility commission (PUC) according to whether a service is deemed "interstate" or "intrastate". Title III governs use of the airwaves for "radio communications," which ultimately included radio and TV broadcasting and cellular phone service; it assigns the FCC responsibility for regulating private sector users and preempts most forms of state regulation. Title VI, added in 1984, governs cable television services, and largely divides authority between the FCC and local authorities. ${ }^{19}$ The 1996 Act essentially preserved these three regulatory "silos" reflected in Titles II, III and VI, depending on the transmission medium: wireline telephone network, wireless, or cable.

The ongoing controversy over video franchising illustrates how jurisdictional differences can matter. As telephone companies deploy fiber closer to the home, they seek to offer video services in competition with cable companies. Although the Cable Act of 1992 barred exclusive video franchises, entrants must still negotiate franchise agreements with many localities, which raises transaction costs and limits exploitation of geographic scale economies. The phone companies have pressed for state and congressional action to streamline the process. By contrast, a satellite-based video competitor would need approval only from the FCC to operate nationally.

Turning to substantive treatment, wireline phone companies are subject to the heaviest regulation (including common carrier duties discussed shortly). The traditional jurisdictional separation model arbitrarily classified part of a phone company's local loop cost as intrastate (the national average since the 1980s is $75 \%$ ) and the rest as interstate; the PUC is responsible for authorizing revenue to cover the intrastate portion and the FCC for interstate. Retail customers pay two fixed monthly charges (one authorized by the PUC, the other by the FCC), that typically cover unlimited local calling; they also pay perminute charges for toll calls, again regulated by the PUC for intrastate calls, and by the FCC for interstate.

Wholesale customers - other carriers - pay "access charges". Before the 1996 Act, other carriers were mainly wireline long-distance carriers. They paid per-minute charges for calls routed through the local phone company's switch where they could be metered "switched access" - both when picking up a call at the originating end and when handing it off for termination. The FCC regulates interstate access charges, and PUCs regulate intrastate. Long-distance carriers also paid fixed monthly charges, known as special access, when leasing dedicated lines to connect directly to business customers, bypassing the ILEC switch. (The FCC has jurisdiction over special access if at least $10 \%$ of the traffic is estimated to be interstate.) The 1996 Act allowed "local" competitors (CLECs) to lease dedicated capacity at lower prices (as UNEs) than for special access. For switched "local" calls between carriers, the Act introduced per-minute termination rates, known as

\footnotetext{
19 The FCC claimed that its ancillary jurisdiction under Title I allowed it to regulate cable TV because the latter affected commercial over-the-air broadcasting over which the FCC had explicit authority. In 1968, the Supreme Court upheld what the authors call "the exercise of this strikingly open-ended regulatory authority" and in 1984 Congress formalized this authority by adding Title VI.
} 
reciprocal compensation, set much below access charges. ${ }^{20}$ These distinctions are central to the live issues of reforming intercarrier compensation and universal service (sections 5.3 and 5.4 below).

Under Title II, wireline telephone companies were regulated as common carriers, ${ }^{21}$ whose defining feature is a prohibition on "unjust or unreasonable discrimination among similarly situated customers". Common carriers do not make individualized decisions; they typically must file tariffs describing their prices and terms of service. Superficially uncontroversial, such nondiscrimination and tariff requirements in practice can significantly restrict flexibility, especially when customized arrangements are needed. ${ }^{22}$ The 1996 Act essentially adopted the FCC's Computer II distinction between "basic" and "enhanced" services under the new terms telecommunications services and information services. Telecommunications services - basic transmission services offered by wireline phone companies - are subject to common carrier regulation under Title II, including the unbundling obligations added by the 1996 Act. By contrast, information services (and entities that provide them) qualify for lighter regulation under Title I, including no unbundling obligations. In addition, providers of interstate telecommunications services must pay into the federal universal service fund (about $10 \%$ of their retail interstate revenues), whereas providers of information services pay only at the FCC's discretion. These distinctions affect competitive parity and universal service reform (sections 5.2 and 5.4 below).

While adding a new set of wholesale-level regulations, the Act also recognized that industry conditions will change over time. Accordingly, it gives the FCC sweeping new discretion to "forbear from applying" most regulations - including for Title II services - if the FCC finds them no longer necessary to protect consumers, or if the FCC finds forbearance is in "the public interest" for other reasons. ${ }^{23}$ Small wonder the FCC is the vortex for incessant lobbying!

The above framework is rife with arbitrary regulatory distinctions, causing several inefficiencies. Different treatment of competitors based on their technology can distort competition in the short run and skew technology choices in the longer run. On the demand side, price differences unrelated to cost differences can distort consumption patterns. And generally, arbitrary differences invite wasteful rent seeking, such as battles over regulatory classification.

\footnotetext{
${ }^{20}$ The 1996 Act tasks the FCC with formulating these new wholesale rules for local competition and the states with implementing them (section 4.4 above), but left retail prices and access charges subject to the dual jurisdiction split.

${ }^{21}$ The authors note that while the legal definition is notoriously circular - "any person engaged as a common carrier for hire" - the usual legal test in telecom is whether a carrier holds itself out to serve any willing customers and allows customers to transmit whatever content they wish using its facilities.

${ }^{22}$ Besides nondiscrimination, the prices and terms of common carriers must be "just and reasonable".

${ }^{23}$ The FCC had long exempted "non-dominant" long-distance wireline carriers from filing tariffs, but by the mid-90s the courts ruled that tariffs were mandatory for all common carrier services. Under separate authority granted by Congress, the FCC in 1994 exempted wireless carriers from most common carrier requirements. The 1996 Act greatly expanded and codified the FCC’s forbearance authority.
} 


\subsection{Technology-based regulatory disparities among competitors}

The authors stress disparate treatment of competitors - regarding common carrier obligations (including unbundling and filing tariffs), universal service contributions, or access charges - for two types of services: broadband Internet access, and voice services.

\subsubsection{Broadband internet access: Telephone vs. cable companies}

When residential broadband access became significant in the late 1990s, telephone companies' DSL offering competed head-to-head with cable-modem service. Pursuant to Computer II, telephone companies had to offer DSL transmission on an unbundled basis to independent ISPs (that use this last mile link along with Internet backbone facilities, owned or leased, to connect consumers to the Internet). Cable companies were never subject to common carrier obligations, including unbundling, and typically offered their cable-modem Internet access services only with their own ISP service. Some local franchising authorities ordered cable companies to offer "open access" to their cable modem service for unaffiliated ISPs. The ensuing torturous litigation, and the disparate treatment of DSL and cable in the interim, illustrates the problems created by messy jurisdictional and service-classification distinctions.

Regarding jurisdiction, cable facilities are normally subject to Title VI regulation, which gives franchising authority to local bodies. Cable modem service, however, supports applications that resemble services regulated under other Titles of the Act: VoIP competes with circuit-switched voice (Title II), and streaming video competes with traditional cable service (Title VI) or video services delivered over the air (Title III). In its 2000 Portland decision, the $9^{\text {th }}$ Circuit ruled that local authorities lacked jurisdiction, on grounds that cable modem included an interstate "telecommunications" component. (Earlier, in the 1990s, the FCC had classified DSL services as exclusively "interstate" and thus under its sole jurisdiction.)

The battle shifted to whether cable modem should be classified as a "telecommunications" service presumptively subject to federal common carrier regulation, as suggested by the Portland decision, or as an "information service". The FCC in 2002 declared the latter. In 2003, the $9^{\text {th }}$ Circuit vacated the FCC's decision. The Supreme Court then reversed the $9^{\text {th }}$ Circuit, classifying cable broadband service as a Title I information service in the 2005 Brand $X$ decision. Later that year, the FCC responded by finally issuing its Wireline Broadband Order governing the telephone companies' competing DSL offering. It declared DSL an "information service" and, after a transition period, lifted (a) the Computer II unbundling obligations, as well as (b) obligations to pay into the federal universal service fund that had been levied on DSL but not on cable modem.

The FCC's action largely eliminated the disparate obligations on the competing telephone and cable company offerings for residential broadband Internet customers (differences remain regarding business customers). However, it took some eight years since the emergence of the market to achieve this outcome. And the disparity could not be justified on traditional market power grounds, because cable modem was considerably in the lead. ${ }^{24}$

\footnotetext{
${ }^{24}$ Cable’s leadership was cited by the D.C. Circuit for its somewhat controversial decision (in USTA I, 2002) to vacate the FCC's policy (adopted in 1999) that allowed "line sharing” - whereby a competitor (CLEC) could lease only the high-frequency portion of a copper loop to offer Internet access via DSL, while paying a very low or zero price on grounds that the ILEC was already recovering the cost of the line from voice service. Observe that CLECs may still offer DSL by leasing and paying for the functionality of the entire
} 


\subsubsection{Voice services: Circuit-switched vs. VolP}

Traditional landline circuit-switched voice (PSTN) increasingly competes with mobile wireless voice service and with VoIP. The number of switched-access telephone lines to end users (business and residential) fell from 192 million in December 2000 to 178 million in December 2004 and 168 million by December 2006 (FCC, 2007b). Over the same period, mobile wireless subscribers rose from 101 million to 181 million and 230 million. VoIP subscribers reached almost 7 million in mid-2006, more than doubling in a year, and have grown rapidly since then, especially for cable companies. ${ }^{25}$ Yet regulation still handicaps wireline telephony, especially against VoIP.

Mobile wireless carriers were exempted by the FCC in the early 1990s from various common carrier obligations, including the filing of tariffs and prohibitions on selling bundled services such as a discounted phone conditional on a longer service contract (chapter 8). By contrast, the FCC could not unilaterally do the same for intrastate services of wireline voice carriers, even if it were to find they lacked market power, because it shares jurisdiction with the states. In addition, wireless calls within a Major Trading Area pay "local" termination rates (reciprocal compensation), yet some such calls are interstate and if provided by a wireline carrier would pay interstate access charges that are at least three times as high (section 5.3 below).

VoIP is where access charges create the greatest disparity versus PSTN long-distance calls. The authors provide a lucid discussion of how VoIP works and the regulatory issues (chapter 6). In all its variations, VoIP refers to voice communications that use the Internet protocol and are routed over packet-switched rather than circuit-switched networks. Today, residential VoIP service is available mainly to consumers with a landline broadband connection, DSL or cable modem.26 The VoIP seller may be the broadband provider itself (telephone or cable company) or another party such as Vonage. (Vonage supplies an adapter that plugs into the broadband connection and has an IP address to which calls destined for that subscriber are routed.)

The key economic distinction is that voice calls traveling as data packets are not metered on a per-minute basis. A VoIP call therefore avoids access charges as long as it bypasses the PSTN, yielding a significant artificial advantage over circuit-switched long distance calls. Specifically, a provider of the latter pays access whenever the call originates or terminates with a different phone company. On the origination end, this scenario is increasingly rare: with the decline of independent IXCs, most consumers now obtain alldistance voice services from the same phone company. But on the terminating end access payments remain important, since the sender and receiver of a long-distance call are often served by different phone companies.

Now consider a VoIP provider. Calls from its subscribers go directly to its data network and thus avoid paying originating access to the local phone company. If the called party is also a VoIP customer, the call will bypass the PSTN entirely and avoid any

loop, so on paper there is still a disparity versus cable companies that are not subject to such unbundling. But in practice, the option of paying for the entire loop is fare less attractive than leasing only the high-frequency portion under line sharing.

${ }^{25}$ For mid-2006 Telegeography (www.telegeography.com/cu/article.php?article_id=13789) reported the following numbers of VoIP customers: Vonage 1.8 million, Time Warner 1.6 million, Cablevision 1 million, and Comcast 0.7 million. By mid 2007, Vonage had 2.45 million and Comcast surged to 3 million. www.usatoday.com/tech/products/services/2007-08-09-vonage-loses-voip-subscribers_N.htm.

${ }^{26}$ Mobile wireless calls today are still largely circuit-switched (though this may change as mobile networks expand their capacity to handle data applications). 
payment also for termination. ${ }^{27}$ (This avoidance occurs even when the called party obtains its VoIP service over DSL, in which case the VoIP call is delivered over the same telephone line as would a circuit-switched call.) Since terminating access charges are several cents per minute (section 5.3), the difference is significant. As more consumers adopt broadband connections, VoIP will attain a growing artificial cost advantage in call termination over circuit-switched long-distance service.

Outside of access charges, the FCC has largely moved to treat circuit-switched voice and VoIP uniformly. The FCC distinguishes between VoIP services that are interconnected with the PSTN - the VoIP customer is assigned a phone number and can communicate with any PSTN subscriber (a softswitch converts the call from the IP to the PSTN format or vice versa) - and those that are not interconnected. Interconnected VoIP includes services offered by the cable companies or Vonage; non-interconnected VoIP includes computer-to-computer calls, such as today's Skype services, that only allow communication between users of that service. The FCC classified non-interconnected VoIP as an "information service" and chose to exempt it from contributing to the federal universal service fund (I will revisit this issue). It has deferred classifying Interconnected VoIP as an information service or telecommunications service, but since 2006 has required providers to comply with E911 requirements and contribute to the federal universal service fund, as it has done also for wireless carriers (see Preface). ${ }^{28}$

VoIP offers considerable real benefits, such as enabling innovative services and allowing businesses to cut costs by consolidating voice and data services on a single packet-switched network. But access charges give it an artificial boost, leading to premature obsolescence of the circuit-switched network. As the authors stress, the efficient response is to reduce access charges closer to marginal cost, a thorny political challenge discussed shortly.

\subsection{Intercarrier payments}

There are dramatic prices differences, unrelated to marginal costs, in the regulated prices that carriers may charge for access to their networks. Two prominent examples, discussed below, are the leasing of dedicated capacity to carry "local” versus "long-distance" traffic, and the myriad of per-minute termination charges based on this same distinction and other criteria. Of course, such differences can be compatible with economic efficiency if they reflect efficient price discrimination. ${ }^{29}$ But they generally do not. When affecting

\footnotetext{
${ }^{27}$ If the called party is a PSTN subscriber, the VoIP call must be converted to circuit-switched format before delivery hence, can be charged a terminating rate. The exact rate is uncertain, but on average will be lower than for a circuit-switched call between the same points. Specifically, the FCC ruled (in November 2004) that VoIP services are "interstate", thereby preempting state access charges (chapter 6), but has not yet determined the applicable termination rate. VoIP providers would argue for a low rate, as applies to local calls (or to ISP-destined calls), while the terminating phone company would argue for the higher interstate access charge paid by regular long-distance calls (chapter 9). But even if the FCC decides that interstate access applies, VoIP would enjoy a terminating advantage since circuit-switched calls often pay intrastate access charges that on average are more than double the interstate rate (section 5.3 below).

${ }^{28}$ The authors sensibly support the FCC's attempts to ensure consistent national treatment of VoIP and prevent “[B]alkanizing Internet-related services into 50 ... state-level common carrier regulation” schemes. They caution that, despite the FCC's assertion of exclusive federal jurisdiction, significant uncertainty remains over the legal characterization and jurisdictional treatment of VoIP services.

${ }^{29}$ Therefore, the authors' comment (chapter 9) that "identical functions should be compensated equally" is too sweeping if taken literally; but it is correct in their specific context of pricing call termination for VoIP versus circuit-switched calls, and elsewhere the authors stress that price discrimination can be efficient.
} 
competitors' costs, such differences can distort competition (as with access charges avoided by VoIP but not circuit-switched calls). Independent of competitive distortions, they invite wasteful arbitrage, such as re-routing calls to disguise their origin, and skew consumer choices between services whose retail prices reflect different access charges (such as intrastate vs. interstate calls).

\subsubsection{Leasing dedicated capacity}

An incumbent carrier (ILEC) often leases to another carrier a high-capacity dedicated circuit for a flat fee, typically connecting the other carrier to a large business customer. This involves capacity rights on a combination of (a) the loop from the customer to the ILEC's central office and (b) the transport link to another central office where the second carrier's equipment interconnects. When such capacity is leased by a long-distance carrier it is priced as "special access", typically much higher than when leased by a competing local carrier as an "enhanced extended link" (EEL) at TELRIC-based prices that apply to unbundled network elements (chapter 3). If special access usage were instead priced as EELs, the difference would be billions of dollars.

The FCC has sought to limit eligibility for EEL pricing by requiring that at least a certain percentage of all traffic on the dedicated capacity be "local". This raises two issues. First, it is increasingly harder to identify the type of traffic. Dedicated access traditionally was used mainly to carry multiple circuit-switched voice calls, whose origin and destination could be readily identified, but it is increasingly used to carry also data traffic that lacks such ready identifiers. (A carrier can use dedicated access transmission capacity to transport circuit-switched and/or packet-switched traffic, by connecting different switches.) Second, and more fundamental, making a distinction is increasingly pointless since carriers generally are moving away from specializing in local versus long-distance service to competing in all-distance service.

\subsubsection{Per-minute termination charges, arbitrage, and reform}

Intercarrier payments are also substantial for traffic that is charged per minute. In 2005, the last year for which statistics are available, total access charges were almost $\$ 10$ bn ( $\$ 6.2$ bn intrastate, $\$ 3.7$ bn interstate), and reciprocal compensation charges added about $\$ 1$ bn (Lande et al, 2007). The per-minute charges differ greatly based on a call’s regulatory designation, as chapter 9 comprehensively explains.

A central distinction is between "long-distance" and "local" traffic. Access charges for long-distance calls were traditionally priced well above marginal cost, a pattern justified by regulators on grounds of cross-subsidizing other services such as basic local service. ${ }^{30}$ The 1996 Act introduced reciprocal compensation: carriers must charge each other the same termination rate for local traffic. This rate is much lower than access charges since it must be based on the incremental cost of termination rather than embedding a crosssubsidy.

\footnotetext{
30 This policy rested partly on the dubious premise that long-distance remained a luxury service. Within the pre-1982 vertically integrated AT\&T, the cross-subsidy involved a complex and opaque system of internal accounting. For long-distance calls carried by AT\&T to or from independent local phone companies such as GTE, the cross-subsidy was implemented by requiring AT\&T to pay inflated toll settlement charges. This approach was formalized and extended to the local Bell companies after they were separated from AT\&T: at each end, origination and termination, long-distance calls were required to pay inflated access charges (intrastate or interstate) per minute.
} 
Consider the discrepancy in termination rates for various calls. (A long-distance call also pays originating access if the caller's long-distance and local providers are different.) Within long-distance, intrastate access charges are generally higher than interstate because the FCC has moved faster than most states to reduce charges under its jurisdiction. And termination rates are generally higher for small, "rural" ILECs than for large ILECs because of a regulatory tradition of favoring smaller local phone companies. ${ }^{31}$

The differences are striking. Estimated volume-weighted average termination rates, in cents per minute for 2006, are as follows. ${ }^{32}$ Local voice calls had a reciprocal compensation rate of 0.2. Interstate calls paid access charges ranging between 0.6 to a large ILEC (or CLEC) and 1.8 to a small ILEC. For intrastate calls, the range was 2.5 to a large ILEC and 5.1 to a small ILEC. (For wireless calls, the termination rate was 0.2 for intraMTA calls and 0.6 for interMTA.) Thus, on average, an intrastate call terminated by a small ILEC would be charged twenty five times more than a local call from a competitor for an identical termination function.

Even differences of a fraction of one cent can alter carriers' behavior, as demonstrated by the dial-up ISP controversy (chapter 9). In the late 1990s, residential consumers obtained Internet access mainly by having their computer modem dial a local circuitswitched call to their ISP, which linked them to the Internet and converted the digital Internet traffic into circuit-switched analog signals compatible with the consumer's phone line. These dial-up calls were virtually all one-way: from subscribers to the ISP. Many CLECs began specializing in hosting ISPs - and paying ISPs to be their customers. Why? Because the ISP's subscribers typically obtained phone service from the ILEC, which then had to pay the CLEC termination charges for all calls from those subscribers to the ISP. The reciprocal compensation rate, well under one cent at the time, was still sufficiently above the incremental cost of termination to foster this arbitrage. ${ }^{33}$

Since terminating-access charges for long-distance calls are much higher than reciprocal compensation rates, the arbitrage incentives are considerably stronger. One class of schemes involves disguising the origin of a long-distance call to make it appear as local by re-routing it. Re-routing was common for international calls, to arbitrage different termination rates that a given country has with other countries (Malueg and Schwartz, 2001), and according to industry observers is now a significant phenomenon also for domestic U.S. calls. (The authors report estimates that as much as $20 \%$ of traffic is of unknown origin.) And, as noted earlier, VoIP technology provides additional ways to avoid access charges.

Total access payments will have declined considerably since the 2005 mergers of the largest independent long-distance companies with the two largest local phone companies, AT\&T-SBC (which in 2006 acquired BellSouth) and MCI-Verizon, since more traffic now stays internally. But access payments still involve billions of dollars. Observe that the level of access charges is economically relevant even if traffic is balanced between two

\footnotetext{
31 The authors note wryly (chapter 10) that the definition of a carrier as "rural" hinges on its small customer base rather than the "rustic qualities of its territory" since a Bell company serving an adjacent territory would not be classified as rural.

${ }^{32}$ The ensuing figures come from ICF (2005), updated to reflect that the FCC since then has reduced interstate CLEC termination rate from 1.8 cents to 0.6 cents per minute.

${ }^{33}$ Malueg and Schwartz (2003, section VI) discuss a related example. In 2000, the North Carolina PUC disallowed over $\$ 150$ million in reciprocal compensation to a CLEC from BellSouth triggered by a large business customer that leased a line from BellSouth for a fixed monthly fee and made continuous computergenerated calls to the CLEC, which shared the profit with that customer.
} 
networks, because terminating access is part of a carrier's marginal cost of offering longdistance calls. In practice, significant net transfers do remain between networks, from those long-distance or wireless carriers that are less integrated into local access to those that are more extensively integrated and, more importantly, from long-distance or wireless carriers generally to small ILECs.

The resistance to reducing access charges comes largely from small ILECs. An important reason is that long-distance carriers of "telecommunications services" are obliged to charge geographically averaged retail prices. The 1996 Act, codifying prior regulatory practice, requires prices for interstate calls of a given distance to be uniform across states regardless of differences in access charges or other costs; in addition, state PUCs can require inter-exchange calls within a state to be no higher in rural/high-cost areas than in urban areas, so some geographic rate averaging occurs also for intrastate calls (chapter 9). Importantly, a given increase in the termination rate of a local carrier will induce a smaller rise in the uniform retail price of long-distance calls for originating carriers the smaller is the local carrier, because fewer calls are affected when the local carrier is smaller. Thus, smaller carriers will suffer a smaller percentage reduction in incoming calls when raising their termination rates than would large carriers. Geographic averaging rules for retail long-distance prices thereby lead smaller local carriers to seek higher termination rates than preferred by large carriers. Even if such rules were repealed, a bias may remain if other factors (for example, transaction costs or simplicity in marketing) limit carriers' ability to set different retail prices depending on a call's destination. But the geographic averaging rules surely do not help.

Besides the inflated average level of access charges, a serious flaw with today's "crazy-quilt" system is the host of different rates depending on regulatory classifications. In addition to the distinctions between interstate and intrastate calls, large vs small terminating carriers, and wireless vs. wireline calls, there are separate rules - and sometimes ambiguity - for ISP-bound calls, VoIP, and calls that transit across the facilities of an intermediate carrier. (I will not even attempt to describe the full panoply, but insomniacs should try pages 306-8.)

There is consensus that the system is broken, but less agreement on the fix. The FCC has begun a process whose ultimate goal is a unified system of intercarrier compensation for exchanging all types of traffic (except among Internet backbones, that are unregulated). The theory of efficient interconnection pricing is complex and sensitive to industry details (Armstrong, 2002; Voglesang, 2003; and Peitz, Valletti and Wright, 2004). Pragmatically, the authors see two serious candidate approaches to a unified system. One is today's calling-network-pays regime but with access charges stripped of cross-subsidies and lowered to marginal costs. The other is bill-and-keep: abolish termination charges and let carriers recover revenue only from their retail customers. The authors discuss the pros and cons of these approaches, ${ }^{34}$ and the uncertainty over the FCC's legal authority to order billand-keep, especially for intrastate toll calls.

\footnotetext{
${ }^{34}$ Bill-and-keep has important advantages, including addressing the "terminating access monopoly" problem - a carrier's incentives to seek excessive termination rates because the retail price effects fall on customers of other carriers rather than its own (for example, DeGraba, 2000). However, the authors overstate the case when writing (p.320) that bill-and-keep is uncontroversial if traffic between carriers is balanced (equal inbound and outbound). Any reciprocal termination rate then yields no net transfer, but the rate chosen will affect the pricing of outbound calls, hence, the call volume. A rate of zero may not be efficient if termination costs are sufficiently large ("may not" because if calls generate value also to the receiver, a termination discount below marginal cost is needed to internalize this externality). Asymmetries between networks in
} 
Actual reform efforts have focused on lowering various access charges piecemeal. For interstate access, the FCC in 2000 largely adopted the proposals of a broad industry group CALLS (Coalition for Affordable Local and Long Distance Service) to reduce access charges and raise the flat monthly fee as well as the universal service fund that supports local carriers in high-cost areas (discussed further below). ${ }^{35}$ Attempts to reduce intrastate access charges have moved slower. In 2005 another industry coalition, the ICF (Intercarrier Compensation Forum), offered a unified approach to reducing interstate and intrastate termination rates for all types of traffic, but the initiative stalled. A successor, the Missoula Plan, was proposed by some ICF members, state regulators, and smaller IlECs, but its status is uncertain. Thus, reforming intercarrier compensation remains work in progress.

\subsection{Funding universal service}

Another area fraught with arbitrary regulatory distinctions and in serious need of reform is the funding of universal service (chapter 10). At the outset, the authors usefully recap that the concept has long strayed from the narrow goal of assuring telephone service for people who otherwise would not subscribe (Kaserman and Mayo, 1997). It includes implicit or explicit subsidy programs unrelated to this goal or to income levels, notably, programs to keep retail prices for basic residential local service below cost in high-cost areas, typically, lower-density rural areas. Like many economists, they caution that there is no uncontroversial policy justification for such subsidies to high-cost areas - including subsidies that often cover second phone lines.

With these caveats, turn to how the programs work. In the traditional regulatedmonopoly era, the tool was implicit cross-subsidies. The deficit from holding some prices below cost was covered by letting the telephone company over-price other services, such as access charges for long-distance calls (see also chapter 2). This system was both inefficient and vulnerable to competition for the over-priced services. The 1996 Act reaffirms the goal of keeping rates "affordable" and "comparable" geographically but calls for replacing some cross-subsidies with explicit subsidies from a federal "high cost fund”. ${ }^{36}$ The FCC's High Cost Fund is about \$4.5 billion - over half of the total FCC's universal service fund and the fastest growing segment. ${ }^{37}$ Our focus is on who pays into the Fund.

The Act calls for competitively neutral assessments, determined by the FCC, on carriers that provide "interstate telecommunications services". The FCC initially stated that

various dimensions also can undercut the efficiency of bill and keep (or other symmetric rates). For example, if one carrier has a much larger geographic coverage than another then traffic between their subscribers will typically travel much further on the large network, whose provider ultimately must make greater investment in capacity per subscriber. Consistent with this factor, Internet backbone carriers offer bill-and-keep ("peering”) only to carriers whose geographic network is of comparable reach.

${ }^{35}$ Chapter 10. Similar but more modest changes were made to interstate access for rural carriers in the FCC's 2001 Multi-Association Group proceeding.

${ }^{36}$ The FCC's universal service fund comprises four programs: one subsidizes phone service to low-income households, another subsidizes Internet broadband connections to schools and libraries, a third does the same for rural healthcare facilities, and the fourth is the High Cost fund (which until now has paid only for phone service, though the 1996 Act describes universal service as an evolving standard).

${ }^{37}$ Even so, the High-Cost Fund was not intended to replace all cross-subsidies, but mainly to reduce interstate access charges and a small portion of intrastate cross-subsidies. Much work remains to be done by the states in bringing down intrastate access charges. 
contributions should be based on a carrier's interstate retail revenues and perhaps also intrastate, but in 1999, the $5^{\text {th }}$ Circuit ruled that the FCC could only base contributions on interstate revenues. The authors note that the proliferation of bundled packages of interstate and intrastate services, as well as of non-telecommunications services such as Internet access and video, has made it increasingly hard to identify the "interstate telecommunications" component. Hamstrung by this limitation, the FCC is put in a position of declaring (in June 2006) with illusory precision that the interstate share of calls for wireless carriers is presumed to be $37.1 \%$ and for VoIP $64.9 \%$.

The limitation to "telecommunications services" is also increasingly problematic. Computer-based services not classified as "telecommunications" are increasingly substitutable for voice and fax services offered over traditional phone lines, and exempting the former from universal service contributions gives them an artificial competitive advantage. Although the FCC has required contributions from "interconnected VoIP" it has exempted non-interconnected VoIP, such as computer-to-computer voice calls, as well as Email (section 5.2.2 above). Yet, both divert business away from phone use. The authors discuss potential reforms that would base contributions on different metrics, such as how many connections or telephone numbers a carrier offers, but they note economic or jurisdictional problems with each. For example, connections can vary greatly in their importance, and some long-distance carriers do not assign phone numbers.

Ultimately, since the goals of the "universal service" programs are largely redistributive and not narrowly linked to the traditional telecommunications industry (unlike the fostering of network effects through increased phone adoption), the efficient funding mechanism is presumptively a broad-based tax system.

\section{Policy reform}

\subsection{Substantive changes}

The book's two main policy prescriptions, expressed in chapter 13, flow naturally from the foundation laid in preceding chapters.

One prescription is to remove artificial regulatory distinctions, especially between transmission facilities that are each becoming increasingly capable of delivering various IP-based services. The authors call for adopting a "horizontal" or "layers" model of regulation (see also chapter 6) based on the functions performed at each of the Internet's main layers: physical, logical, applications, and content. Regulation should focus on the layer where substantial market power exists, regardless of the technology used to provide that function.

While the suggestion is sensible in spirit, the particular layers model raises some caveats. Layers are a useful concept but do not always track actual hardware or software implementation. Moreover, it is not always possible to ignore services and only analyze layers because the market power of a given technology in a particular layer can vary across services. For example consider transmission facilities at the physical layer. Cable facilities may face stronger competition to their VoIP services (from mobile wireless and landline phone companies) than in broadband Internet access (where, for now, wireless is not as strong an option). The authors acknowledge such concerns when cautioning (chapter 6) that the layered structure of digital telecommunications systems "should be only the 
beginning, not the end, of serious policy analysis”. The details of a satisfactory new approach therefore remain to be fleshed out. But its core elements are clear. It should be technologically neutral among facilities capable of providing the same services; and it should target only those segments exhibiting substantial market power, recognizing that the identity of such segments can shift with changes in technology or demand.

The other main proposal is to be more circumspect in imposing intrusive access regulation and give market forces a chance to play out. They urge moving away from preemptive ex ante regulation, especially in last mile access, towards an antitrust type approach that tackles most exclusionary conduct once it occurs rather than prohibiting in advance. Of course, there is a downside since delayed intervention can allow harm. The authors recognize the tradeoffs and that access interventions have their place (chapter 1). Their call for a higher intervention hurdle is not based on ideology but on recognizing two salient industry developments.

First, monopoly is rare in today's telecom industry - most segments exhibit significant competition or plausible prospects. Before tagging something as an enduring bottleneck worthy of intervention, market forces should be given some time to try to erode the market power. Second, the historical record calls for a seasoned appreciation of the limits and costs of intervention (what the authors call "humility"), culminating with the sobering experience of the 1996 Act. The technical implementation difficulties and the morass of legal and regulatory disputes have not been a pretty picture. Moreover, the role of the Internet in enabling facilities-based competition for any digital services delivered over various facilities was largely overlooked. The prospects that future access regulation in telecommunications would be significantly more efficient are undercut by the rapid change and complexity of this industry.

\subsection{Institutions}

The authors also offer thoughtful perspectives on the institutional aspects of policy reform (chapter 13). Although they favor moving telecom regulation away from prescriptive rules towards back-end enforcement as in antitrust, they recognize that significant intervention in pricing and other access terms will likely be with us for some time. This raises an important institutional question: should prime oversight of telecom competition reside with a specialized agency like the FCC or with generalist antitrust courts?

Like many economists, the authors see generalist courts as less vulnerable to interest group pressures. ${ }^{38}$ They term this advantage "neutrality" - resolving competition policy issues on broad welfare grounds rather than favoring special interests. Besides this possibility of regulatory capture, however, specialized agencies invite rent seeking: whether or not the ultimate outcome is "neutral", there will likely be costly lobbying and overregulation. The authors recognize this inefficiency, but could have been clearer that it is an independent issue beyond "neutrality". ${ }^{39}$ Countering some FCC critics, they correctly

\footnotetext{
${ }^{38}$ An amusing exception involves legal forum shopping. In 1997, two Bell companies elected to challenge the constitutionality of certain provisions of the 1996 Act in a federal district court in Wichita Falls, Texas, obtaining a favorable ruling on New Year's Eve. This fleeting victory was reversed the following year.

${ }^{39}$ The economics literature has stressed this issue when addressing the paradox of selective intervention. The paradox is that a single integrated firm seemingly should always be able to perform better than separate entities by intervening internally only when intervention increases overall profit (Williamson, 1985). A compelling reply is that intervention cannot be confined to be "selective" - once there is an authority with the power to intervene, it will be lobbied to intervene also for distributional reasons (Holmstrom and Tirole, 1989 and Milgrom and Roberts, 1992, chapters 6 and 8).
} 
note that such problems are endemic to any specialized agency tasked with overseeing an industry. They see no obvious institutional reform that would insulate the FCC from outside pressures. But on balance they still favor the FCC over generalist courts because of its advantages in expertise and, potentially, “determinacy”.

The expertise argument is clear. Generalist judges lack the industry knowledge and resources to resolve pricing and technical disputes over network access in complex industries, and are understandably leery of trying. In the relatively few cases when courts have ventured into access regulation to address monopolization, the process typically has been problematic.

By "determinacy" the authors mean providing clearer and faster guidance about the relevant rules and how they will be applied. They concur with Judge Brandeis that it is often more important "that the applicable rule of law be settled than that it be settled right”. Determinacy is seen as especially important in the telecom industry where large new investments must be made and adapted to rapidly changing conditions. Their discussion of determinacy offers interesting insights about the FCC's internal structure and its relations with other policy actors.

In theory, ex ante regulation should be superior to ex post antitrust enforcement in providing determinacy; antitrust relies heavily on the evolution of a body of case law that can take considerable time and produce inconsistent rulings by different courts. In practice, however, the FCC process also can exhibit very long delays and the associated uncertainty.

The authors lay part of the blame on the FCC's structure. The five commissioners are appointed by the President but must be confirmed by Congress and can be removed only for cause. This structure provides checks and balances. But it can also produce major inefficiencies. These include lack of clear accountability by commissioners and conflicting agendas, spawning delays and messy split-the-baby compromises. The authors perceive these flaws as sufficiently harmful in the rapidly changing telecom sector that the commission structure may be inferior to a more centralized model, such as an agency headed by a single person and residing within the executive branch (like the Food and Drug Administration).

But the FCC is hardly the sole culprit on the (in) determinacy front. The authors also criticize excessive second-guessing by the circuit courts that review FCC rulings. They stress that judicial deference to an administrative agency is justified not just by its presumed expertise but also by the need to provide certainty. While judicial intervention is sometimes appropriate, the authors urge courts to remember the value of determinacy and pick their fights more selectively.

Congress also gets much of the blame because of how it wrote the 1996 Act. Like many observers, the authors criticize the Act for being exceptionally vague in places, and contradictory in others. They portray this outcome as unsurprising, since the Act was largely a political compromise between the local Bell companies and the long-distance carriers, and attempting to resolve the most contentious issues up front would have likely derailed any major legislation. This observation begs the question of whether the Act as written was preferable to no Act at all. It would have been interesting to learn the authors' thoughts on this. Despite its many flaws, the 1996 Act has some compelling virtues, notably, articulating an explicit policy preference to replace regulated monopoly with competition wherever possible in the telecom sector.

Although considerable vagueness in the Act was necessary for passage, the authors note that superfluous indeterminacy and litigation arose because Congress was not 
sufficiently clear on the roles delegated to the FCC and the states. This is exemplified by the six years and two Supreme Court decisions it took to resolve the disputes over the FCC's TELRIC rules.

While agreeing that the Act's language was insufficiently clear in assigning roles between the FCC and the states, the authors are split on the substantive question of how much of the "details" work should be left to the states. Weiser stresses the benefits of experimentation and flexibility to address diverse local conditions. Nuechterlein worries about delay, confusion and duplication from diffusing regulatory authority among fifty states. (Similar concerns have been voiced elsewhere about the antitrust review of multinational mergers by multiple jurisdictions even where the competition issues are quite similar.) In any event, the authors observe that debates over the appropriate role for state commissions in telecom policy are far from over.

Both authors agree that costly duplication and delay occur in the review of telecom mergers. Such transactions require approval both by the FCC (for license transfers) and by a federal antitrust agency, either the DOJ or FTC. The authors argue that, at best, some of the FCC's review is superfluous when the issues have a relatively tight competition focus (as distinct from other goals the FCC also considers, such as diversity or localism). Beyond redundancy, the FCC comes in for especially harsh criticism - not wholly undeserved - for its substantive approach to merger approval. Whereas the DOJ or FTC can only block or modify a merger if they can persuade a court that the merger otherwise is likely to substantially lessen competition in violation of the Clayton Act, the FCC has considerable unilateral power. It operates under the more amorphous standard that a merger must advance the "public interest", and it gets to decide if the standard is met. The FCC has used this power to obtain "voluntary" commitments from the parties as a condition for merger approval - commitments that are sometimes unrelated to specific concerns raised by the merger. This is not good public policy. Regrettably, some states have extracted similar commitments using their state-level approval process.

Jurisdictional issues among federal agencies may increasingly arise also for nonmerger matters, as the FTC has recently signalled strong interest in competition and consumer protection aspects of Internet policy. In general, some serious thinking is needed about the appropriate role of the states and the various federal agencies in telecom policy.

\section{Conclusion}

The book covers a lot of ground, some of which was not addressed in this review. It comprehensively identifies the key policy issues in this huge and vibrant industry, and offers instructive lessons from the past. Scholars, practitioners, regulators, and others interested in the field of telecom policy will find the book an excellent resource.

\section{$8 \quad$ References}

Areeda, P. (1990) "Essential Facilities: An Epithet in Need of Limiting Principles," Antitrust Law Journal, 58: 841-53. 
Armstrong, M. (2002) “The Theory of Access Pricing and Interconnection,” in M. Cave, S. Majumdar and I. Vogelsang (ed.) Handbook of Telecommunications Economics, Elsevier Publishers: Amsterdam.

Armstrong, M. (2006) "Competition in Two-Sided Markets," RAND Journal of Economics, 37: 668-91.

Brennan, T.J. (1987) "Why Regulated Firms Should Be Kept Out of Unregulated Markets: Understanding the Divestiture in United States v. AT\&T,” Antitrust Bulletin, 32: 741-93.

Brock, G.W. (1994) Telecommunication Policy for the Information Age: From Monopoly to Competition. Harvard U. Press: Cambridge.

DeGraba, P. (2000) "Bill and Keep at the Central Office as the Efficient Interconnection Regime,” Working Paper No. 33, FCC Office of Plans and Policy.

DOJ. (2007) U.S. Department of Justice, Ex Parte Filing, In the Matter of Broadband Industry Practices, FCC, WC Docket 07-52, September 6. http://www.usdoj.gov/atr/public/comments/225767.htm

Farrell, J. (1996) “Creating Local Competition,” Federal Communications Law Journal, November.

Farrell, J. and P.J. Weiser (2003) "Modularity, Vertical Integration, and Open Access Policies: Towards a Convergence of Antitrust and Regulation in the Internet Age," Harvard Journal of Law \& Technology, 17: 85-134.

FCC (2007a) High-Speed Services for Internet Access: Status as of December 31, 2006. Industry Analysis \& Technology Division, Wireline Competition Bureau, Washington, D.C., FCC, October.

FCC (2007b) Local Telephone Competition: Status as of December 31, 2006. Industry Analysis \& Technology Division, Wireline Competition Bureau, Washington, D.C., FCC, December.

FTC (2007) Broadband Connectivity Competition Policy, FTC Staff Report, June. www.ftc.gov/reports/broadband/v070000report.pdf

Gilbert, R. and M. Katz (2001) “An Economist's Guide to U.S. v. Microsoft,” Journal of Economic Perspectives, 15: 25-44.

Hazlettt, T.W. (2008) “Optimal Abolition of FCC Spectrum Allocation,” Journal of Economic Perspectives, Forthcoming, Winter.

Hermalin, B. and M. Katz (2007) "The Economics of Product Line Restrictions with an Application to the Network Neutrality Controversy," Information Economics and Policy, 19: $215-48$. 
Holmstrom, B. and J. Tirole (1989) "The Theory of the Firm," in R. Schmalensee and R. Willig (ed.), Handbook of Industrial Organization, Volume 1, Elsevier: Amsterdam.

ICF (2005) Comments of the Intercarrier Reform Forum. In the Matter of Developing a Unified Intercarrier Compensation Regime. FCC CC Docket 01-92, filed May 23.

Kaserman, D. and J. Mayo (1997) “The Quest for Universal Service: The Misfortunes of a Misshappen Policy,” in D. Alexander (ed.), Telecommunications Policy: Have Regulators Dialed the Wrong Number? Greenwood Publishing Group: Westport, CT.

Klein, B. (2001) "The Microsoft Case: What Can a Dominant Firm Do to Defend Its Market Position?” Journal of Economic Perspectives, 15: 45-62.

Kwerel, E. and J. Williams (1998) "Free the Spectrum: Market-Based Spectrum Management," in T. Bell and S. Singleton (ed.), Regulators' Revenge: The Future of Telecommunications Deregulation, Cato Institute: Washington, D.C.

Katz, M. (1997) “Ongoing Reform of U.S. Telecommunications Policy,” European Economic Review, 41: 681-690.

Laffont, J.J. and J. Tirole (2000) Competition in Telecommunications. MIT Press: Cambridge.

Lande, J., P. Almoguera, and K. Lynch (2007) Telecommunications Industry Revenues 2005. Industry Analysis \& Technology Division, Wireline Competition Bureau, Washington, D.C., FCC, June.

Malueg, D. and M. Schwartz (2001) "International Telecom Settlements: Gaming Incentives, Carrier Alliances, and Pareto-Superior Reform," Journal of Industrial Economics, 49: 335-77.

Milgrom, P. and J. Roberts (1992) Economics, Organization and Management. Prentice Hall: Englewood Cliffs.

OECD (2006) Network Neutrality: A Policy Overview. Working Party on Telecommunication and Information Services Policies, Organisation for Economic Cooperation and Development, April.

Peitz, M., T. Valletti, and J. Wright (2004) "Competition in Telecommunications: An Introduction,” Information Economics and Policy, 16: 315-21.

Rochet, J.C. and J. Tirole (2006) “Two-Sided Markets: A Progress Report,” RAND Journal of Economics, 37: 645-67.

Schwartz, M. (1986) "The Perverse Effects of the Robinson-Patman Act," Antitrust Bulletin, 31: 20-59.

Schwartz, M. (1997) "Telecommunications Reform in the United States: Promises and Pitfalls,” in. P. Welfens and G. Yarrow (ed.), Telecommunications and Energy in Systemic 
Transformation: International Dynamics, Deregulation and Adjustment in Network Industries, Springer: Heidelberg and New York.

Schwartz, M. and F. Mini (2007) "Hanging Up on Cartefone: The Economic Case Against Access Regulation in Mobile Wireless," attached as Exhibit A to Reply Comments of AT\&T Inc., RM-11361 (FCC filed May 15). http://ssrn.com/absract=984240

Skype (2007) Petition of Skype Communications S.A.R.L. to Confirm a Consumer's Right to Use Internet Communications Software and Attach Devices to Wireless Networks, FCC, RM-11361, filed February 20.

Vogelsang, I. (2003) "Price Regulation of Access to Telecommunications Networks," Journal of Economic Literature, 41: 830-62.

Wallsten, S. (2007) "Everything You Hear about Broadband in the U.S. is Wrong," Progress and Freedom Foundation, Washington D.C., 13 June. www.pff.org/issues-pubs/pops/pop14.13wallstenOECDbroadand.pdf

Williamson, O. (1985) The Economic Institutions of Capitalism. Free Press: New York.

WSJ (2006) “AOL’s Plan to Move Content to Free Site is a Risky Reversal,” Wall Street Journal, B1, 8 June.

WSJ (2007) “Verizon to Open Call Network to Others’ Phones,” Wall Street Journal, B1, 28 November.

Wu, T. (2007) "Wireless Net Neutrality: Cellular Carterfone and Consumer Choice in Mobile Broadband,” Wireless Future Program Working Paper 17, New America Foundation. http://papers.ssrn.com/sol3/papers.cfm?abstract_id=962027\#PaperDownload

Yoo, C. and T. Wu (2006) "Keeping the Internet Neutral?: Christopher S. Yoo and Timothy Wu Debate,” Public Law \& Legal Theory Working Paper 06-27, Vanderbilt University Law School. http://ssrn.com/abstract_id=743167 